\title{
Investigation of temperature dependence of semiconductor detectors used in medicine for radiation measurements
}

\author{
Simay Ozleyis Altunkok ${ }^{1}$, Nina Tuncel ${ }^{2, a}$ and Nazim Ucar ${ }^{1}$ \\ ${ }^{1}$ Süleyman Demirel University School of Science, Department of Physics, Sparta, Turkey \\ ${ }^{2}$ Akdeniz University School of Science, Department of Physics, Antalya, Turkey
}

\begin{abstract}
In this study, the temperature dependence of p-type semiconductor diodes that are a part of in-vivo dosimetry system was assessed in Co-60 photon energy. The collimator and gantry angle on zero degree, SSD 100 $\mathrm{cm}$, field size 20x20 $\mathrm{cm}^{2}$ was selected. The IBA EDP-5, EDP-10 and EDP-20 diode types that included in this study have different thickness of build-up material so the depth of measurements at water equivalent phantom by FC65-p ion chamber was selected at 5,10 and $20 \mathrm{~mm}$. Along the process the room and phantom temperature was measured and recorded $\left(19^{\circ} \mathrm{C}\right)$. The special water filled PMMA phantom was used for diode set-up on its surface and a thermometer for determine phantom temperature was employed. Each type of diodes irradiated separately for one minute and the signal to dose sensitivity and calibration was performed at room temperature $\left(19^{\circ} \mathrm{C}\right)$ by OmniProInViDos software with DPD-12 electrometer. Examination was repeated from $33^{\circ} \mathrm{C}$ to $20^{\circ} \mathrm{C}$ temperatures. The temperature correction factors were found from slope of the linear drawings for each diode types. The obtained correction factor for EDP-5 and EDP-10 was $0.29 \%{ }^{\circ} \mathrm{C} / \mathrm{cGy}$ and $0.30 \%{ }^{\circ} \mathrm{C} / \mathrm{cGy}$ respectively, that higher than recommended factor $\left(\% 0.25^{\circ} \mathrm{C} / \mathrm{cGy}\right)$. While the more fluctuation for EDP-20 was realized.
\end{abstract}

\section{Introduction}

In vivo dosimetry is effective method for finding several types of common errors, such as errors in data transfer or manual adjustments of the treatment plan in radiation therapy [1-3]. It is therefore, a recommended quality assurance (QA) procedure [4-6]. The use of diodes for in vivo dosimetry is described in several publications [7-9]. Both n-type or p-type silicon diodes are commercially available, but only the $\mathrm{p}-\mathrm{Si}$ type is suitable for radiotherapy dosimetry, since it is less affected by radiation damage and has a much smaller dark current. Diodes are used in the short circuit mode with an electrometer, since this mode exhibits a linear relationship between the measured charge and dose. They are relative dosimeters and should be calibrated by applying several correction factors if used as an absolute dosimeter. For instance, the sensitivity of diode on temperature could be calculated by $\mathrm{S}=\mathrm{M} / \mathrm{D}$ equation. $\mathrm{M}$ is the total charge collected by diode during the irradiation and $\mathrm{D}$ is the absorbed dose. Diodes for entrance and exit dose measurements on patient skin are provided with build-up encapsulation and hence must be appropriately chosen, depending on the type and quality of the clinical beams [10]. The real-time in-vivo dosimetry by diode allows checking the prescribed dose for dynamic beam immediately and makes it possible to correct the treatment errors interactively [11-13]. Since
1994, Howlett et al. [14] have shown that the entrance dose measurement by utilizing p-type diodes at photon beams is an effective method of providing an independent verification of dose delivery accuracy. Diodes show a variation in dose response with temperature (particularly important for long treatments), dependence of signal on the dose rate (for different source-skin distances), angular (directional) dependence and energy dependence even for small variation in the spectral composition of radiation beams (important for the measurement of entrance and exit doses) [10].

In this study, the temperature dependence of p-type semiconductor diodes that are a part of in-vivo dosimetry system was assessed in Co-60 photon energy.

\section{Materials and methods}

The dose measurements in Theratronix Co-60 treatment unit, model Theratron 1000-E, were performed (Fig. 1). The mean energy of two gamma ray counterpart with two beta decay is evaluated $1.25 \mathrm{MeV}$ as mono energy gamma for this radioisotope. For in-vivo entrance dose measurements, the diode is calibrated under a standard condition before it is used as an absolute dosimeter. The main correction factors which influence the diode response during the entrance dose measurements are temperature, field size, source to skin distance (SSD),

\footnotetext{
${ }^{\mathrm{a}}$ Corresponding author: ninatuncel@gmail.com
} 
gantry angle (beam direction) and presence of other beam modifiers such as wedges and trays. The collimator and gantry angle was set on zero degree, and the field size at $100 \mathrm{~cm}$ SSD was $20 \times 20 \mathrm{~cm}^{2}$. So, by using this field the irradiation of diode groups was applicable at the same time for assessing temperature dependence. The IBA 3G$p$ Si diode detectors that included in this study were EDP5, EDP-10 and EDP-20 (Fig. 2). The diode die (chip) usually has inherent build-up material placed around the die. The build-up material type and its thickness are chosen in such a way that the effective depth of the measurements is closer to the depth of the maximum dose of the megavoltage photon energy used. The inherent build-up material is usually made of high $\mathrm{Z}$ material so that the physical thickness can be less than that of waterequivalent thickness [9]. The build-up material of EDP-5 is $5 \mathrm{~mm}$ thickness polystyrene with epoxy encapsulation. For EDP-10 and EDP-20 build-up material is stainless steel with epoxy encapsulation that is equivalent to 10 and $20 \mathrm{~mm}$ water thickness respectively. So, the depth of measurements at water equivalent phantom was 5, 10 and $20 \mathrm{~mm}$.

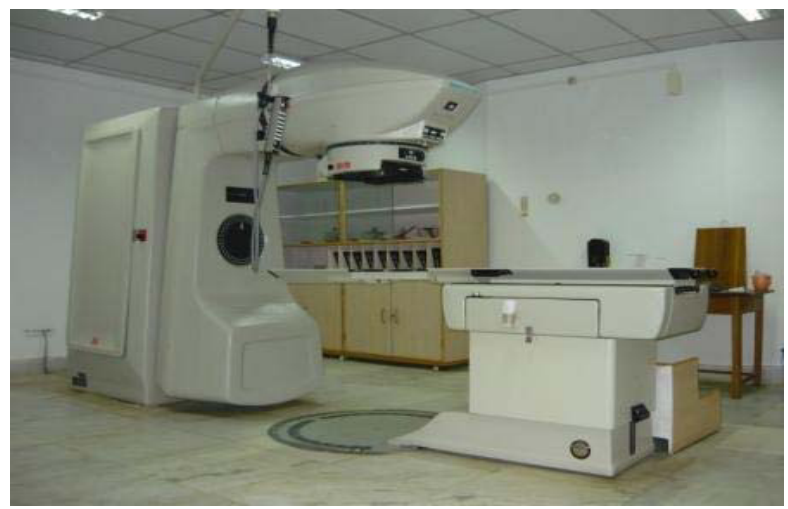

Figure 1. Theratronix Co-60 treatment unit.

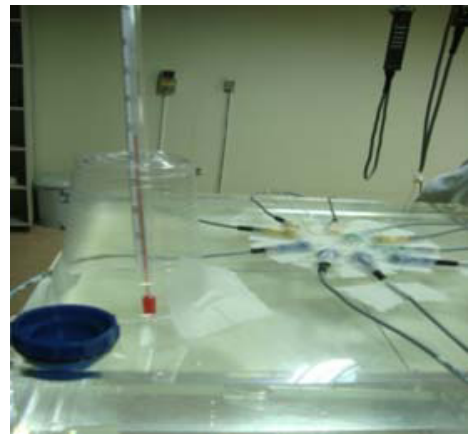

Figure 2. The IBA special phantom with thermometer and EDP-5, 10 and 20 type diodes.

Along the dose measurement process the room and phantom temperature was measured by external in-touch thermometer and recorded as $19^{\circ} \mathrm{C}$. The special water filled PMMA phantom produced by IBA was used for diode set-up on its surface and a thermometer for determine phantom temperature was employed. Each type of diodes was irradiated separately for one minute and the signal to dose sensitivity and calibration was performed at room temperature $\left(19^{\circ} \mathrm{C}\right)$ by OmniProInViDos software with DPD-12 electrometer. By using IBA FC65-p ion chamber and Dose 1 electrometer the absolute dose was obtained at $5 \mathrm{~cm}$ and then the dose at request depths were calculated. For temperature dependence examination the hot water added to special phantom while its temperature reached to $33^{\circ} \mathrm{C}$, then the measurements were started. The manufacturer, IBA, recommended the global correction factor as $\% 0.25^{\circ} \mathrm{C} / \mathrm{cGy}$. The software did not use this factor if the input temperature stood in $19^{\circ} \mathrm{C}$. By this way, the dose readings of diodes reflect the dependence to temperature separately. This examination was repeated at $30^{\circ} \mathrm{C}, 26^{\circ} \mathrm{C}$, $24^{\circ} \mathrm{C}, 23^{\circ} \mathrm{C}, 22^{\circ} \mathrm{C}$, and $20^{\circ} \mathrm{C}$ temperatures. The dose response of each diode based on temperature was tailored.

\section{Results}

The dose response of each diode types regarding to temperature which irradiated at Co-60 treatment unit was evaluated by a linear function. The equations and their regression parameter were obtained. Then, the temperature correction factor of each diode occurred by calculation of the slope of each line. The linear equations and their regressions for four diodes of EDP-5, two diodes of EDP-10, and four diodes of EDP-20 types have been shown in Fig. 3 (a), (b) and (c), respectively. The average of the slope value was calculated as \%0.29, $\% 0.30$ and $\% 0.18^{\circ} \mathrm{C} / \mathrm{cGy}$ for EDP-5, EDP-10 and EDP20 respectively (Table 1 ).

Table 1. The temperature correction factor for each diode type

\begin{tabular}{|c|c|c|c|}
\hline $\begin{array}{l}\text { Diod } \\
\text { Types }\end{array}$ & Serial No. & $\begin{array}{c}\text { Corr. Factor } \\
\left(\%{ }^{\circ} \mathrm{C} / \mathrm{cGy}\right)\end{array}$ & Mean \\
\hline \multirow{4}{*}{ EDP-5 } & 4505 & 0.29 & \multirow{4}{*}{0.29} \\
\hline & 4506 & 0.29 & \\
\hline & 4507 & 0.27 & \\
\hline & 4508 & 0.29 & \\
\hline \multirow{2}{*}{ EDP-10 } & 4955 & 0.29 & \multirow{2}{*}{0.30} \\
\hline & 4957 & 0.30 & \\
\hline \multirow{4}{*}{ EDP-20 } & 5401 & 0.25 & \multirow{4}{*}{0.18} \\
\hline & 5402 & 0.13 & \\
\hline & 5403 & 0.19 & \\
\hline & 5404 & 0.14 & \\
\hline
\end{tabular}

\section{Discussion and conclusion}

The sensitivity variation with temperature of dosimetry diodes is well-known and the temperature-dependence in p-type silicon detectors has also been well described in the literature [15-16]. The diode response variation over time to normal body temperature exposure was evaluated using a $20 \times 20 \mathrm{~cm}^{2}$ field size at a $100 \mathrm{~cm} \mathrm{SSD}$ at Co-60 gamma energy. Under normal conditions, the body skin temperature is approximately around $33^{\circ} \mathrm{C}$. Therefore, the diodes which were initially at normal room temperature $19^{\circ} \mathrm{C}$ were placed on the surface of special phantom. The water temperature was raised to a temperature equal to $33^{\circ} \mathrm{C}$ and was allowed to stay in thermal equilibrium with the surrounding. This experiment simulates clinically the thermal effect on the diode when it comes in contact with patient skin. In these experimental conditions, the temperature of the water bath is different from the 
temperature of the diode. Even after the equilibrium, the temperatures might differ from each other. In our clinical setting, the diode does not stay in contact with the patient skin for more than 2 minutes. But in the especial cases such as total body irradiation the test dose delivery was took placed after the diode was placed on the surface over a period duration of 3-5 minutes and then the total dose delivery was performed. For the next position the test dose delivery were done when they were yet placed on the surface so the total duration of diodes in touch with skin was more than 30 minutes. Therefore, based on our experimental results we concluded that for these diode series and under the especial experimental and clinical conditions, the temperature correction factors are important.

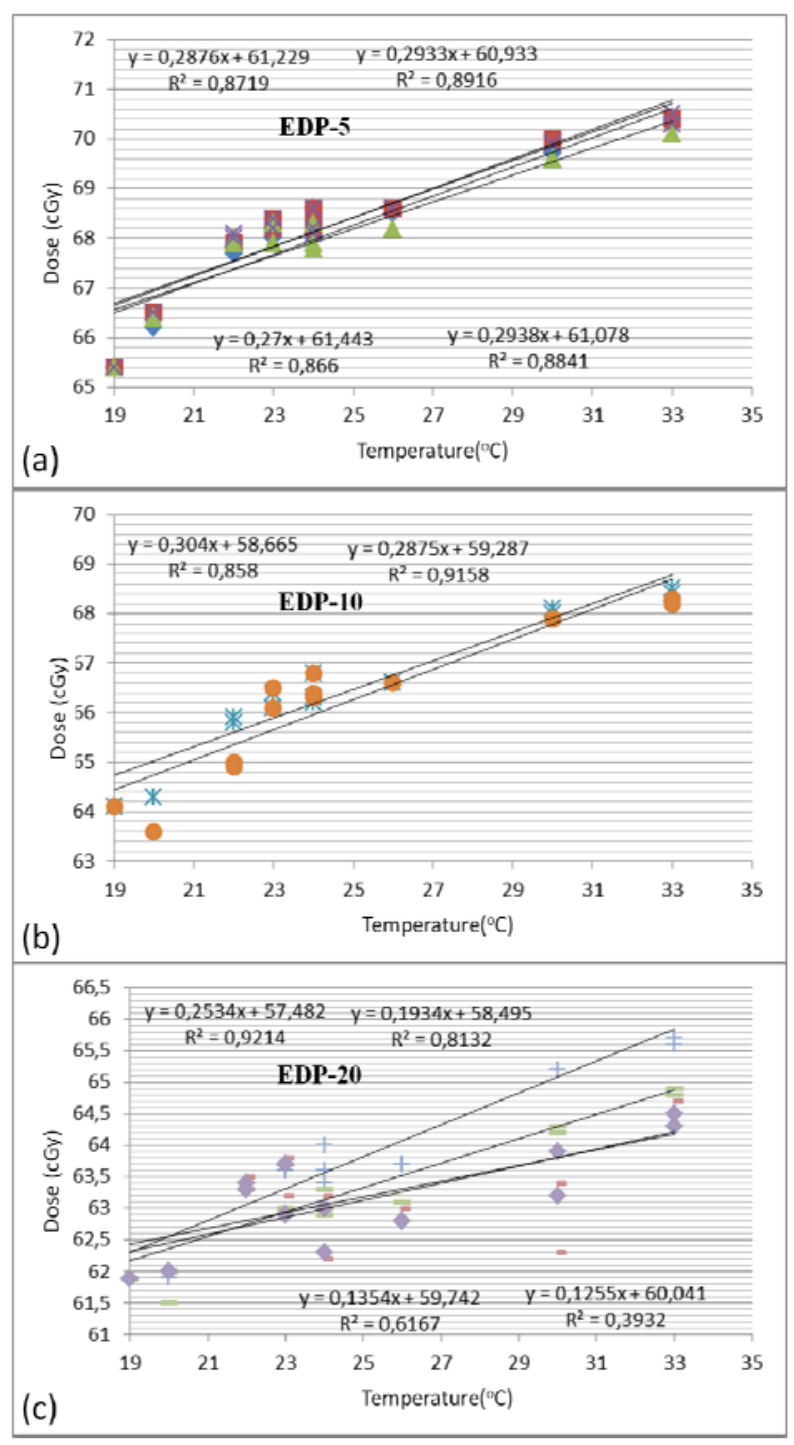

Figure 3. The dose temperature dependence curve and the linear function of each diode to temperature for (a) EDP-5, (b) EDP-10, and (c) EDP-20 type.

The temperature correction factors were found from slope of the linear drawings for each diode types. These factors for EDP-5 and EDP-10 was $0.29 \%{ }^{\circ} \mathrm{C} / \mathrm{cGy}$ and $0.30 \%{ }^{\circ} \mathrm{C} / \mathrm{cGy}$ respectively, that higher than recommended factor $0.25 \%{ }^{\circ} \mathrm{C} / \mathrm{cGy}$ by OmniPro-
InViDos manufacturer. While the more fluctuation for EDP-20 was realized.

According to our experience the heat equilibrium that detected indirectly does not reflect the diode temperature based on the variety on design of each diode type. It will be recommended to applying the direct temperature of each diode that electronically measured by system as an input to software. On the other hand it will be preferred to rewrite the software that is able to accept the temperature for each diode type and then separate temperature calibration factor for each diode will be calculated and possessed.

\section{Acknowledgement}

The Authors would like to thanks all our collaborators from radiation oncology department in Akdeniz University.

\section{References}

1. G. Leunens, et al., Radiother. Oncol. 23, 4 (1992)

2. A. Noel, et al., Radiother. Oncol. 34, 2 (1995)

3. J.H. Lanson, et al., Radiother. Oncol. 52, 1 (1999)

4. ICRU Report 24., International Commission on Radiation Units and Measurements, Oxford: University press, (1976)

5. NACP, Recommendations by the Nordic Association of Clinical Physics (NACP). Acta Radiol. Oncol. 19, 1(1980)

6. G.J. Kutcher, et al., Med. Phys. 21, 4 (1994)

7. J. Van Dam and G. Marinello, Booklet no:1, ESTRO, Brussels (1994)

8. D.P. Huyskens, R. Bogaerts, J. Verstraete, et al., Booklet no:5, ESTRO, Brussels (2001)

9. AAPM Report 87, Medical Physics Publishing, Madison (2005)

10. J. Izewsk and G. Rajan, Chapter 3: Radiation Dosimeters,quality assurance of external beam radiotherapy. In: Radiation Oncology Physics: $A$ Handbook for Teachers and Students. (Ed. E.B. Podgorsak) STI/PUB/1196. pp. 71-99. IAEA, Vienna, Austria (2005)

11. G. Rikner, E. Grusell, Phys. Med. Biol. 28, 11 (1983)

12. G. Rikner, Ph.D. Thesis, Uppsala University, Sweden (1983)

13. G. Rikner and E. Grusell, Phys. Med. Biol. 32, 9 (1987)

14. S. Howlett, L. Duggan, S. Bazley, T. Kron, Medical Dosimetry 24, 1 (1999)

15. E. Grusell and G. Rikner, Phys. Med. Biol. 31, 5 (1986)

16. J. Van Dam, G. Leunens, and A. Dutreix, Radiother. Oncol. 19, 4 (1990) 